\title{
When the Advertised Product Is Not the Target: Multimodal Metaphor in Greek TV Commercials
}

\begin{abstract}
The present paper examines two commercials promoting a Greek airliner, Aegean Airlines. Both commercials involve creative and novel multimodal metaphors through which the specific airline services are compared to the services offered by buses (informing passengers) and the Greek army (catering services and meals). The form and function of the Aegean multimodal metaphors are examined in relation to the generic dimensions of multimodal metaphors in advertising as put forth by Forceville (2007). It is shown that the metaphors in question display, in broad terms, the generic features of multimodal metaphors identified in TV commercials, but violate an established and long-preserved genre-related convention, namely that the target domain of the metaphor coincides with the advertised product. It is argued that the upsetting of generic norms attested in the specific commercials, which introduces the viewer into a counterfactual, albeit wishful, world, has repercussions on the metaphor's conceptualisation and verbalisation. In the paper, the perceived incongruity in the depiction of the main characters ('bus driver' as 'pilot', 'army caterer' as 'air-hostess') is addressed briefly as creating humour.
\end{abstract}

Key words

TV commercials; creative metaphors; multimodal metaphor; generic features of multimodal metaphors; genre-related deviation; verbalisation of metaphor; humour

\section{Introduction}

As Myers (1994) observes, ads constantly strive to create their effect by playing off the audience's expectations of the genre of advertising. The present paper 
is concerned with two commercials that involve creative and novel multimodal metaphors and depart cleverly from the expected norm concerning the relation between metaphors and advertised products.

The two commercials discussed here are part of an advertising campaign promoting a Greek airliner, Aegean Airlines, and were broadcast on Greek television some three years ago. The campaign consisted of three commercials, which, in order of appearance, compared Aegean Airlines to Greek bus services, the Greek army and Greek cruiser boats. The first two ran for about a year concurrently, whereas the third one appeared towards the end of that year and ran concurrently with the other two for a short while before the broadcasting of the particular campaign came to an end. This paper discusses the first two of these commercials, named 'Bus' and 'Army'.

At first glance, both commercials have a common feature: they involve multimodal metaphors through which the specific airline services are compared to the services offered by buses (informing passengers) and the Greek army (catering services and meals). The metaphors in question display, in broad terms, the generic features of multimodal metaphors identified in TV commercials (Forceville, 2007), but violate an established and long-preserved genre-related convention, namely that the target domain of the metaphor coincides with the advertised product. The commercials of this campaign, created by an advertising company ap-

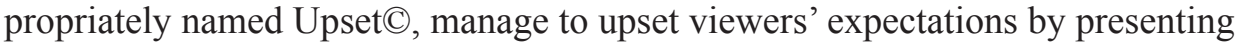
a fictional world where the advertised commodity is in fact the superior-quality source domain, and not the inferior-quality target domain, of the metaphor. These a-typical commercials, which have not been discussed so far in the relevant literature, deserve our full attention, as their step-by-step interpretation can deepen our understanding of how metaphors are used and function in advertising.

\subsection{Aims of the paper}

Based on conceptual metaphor theory (CMT) which defines metaphor as "understanding and experiencing one kind of thing in terms of another" (Lakoff and Johnson, 1980: 5), and also drawing upon Forceville's (2004, 2005 and 2007) work on multimodal metaphors in commercials, the present paper sets out to discuss the metaphors involved in the 'bus' and 'army' commercials of the Aegean Airlines advertising campaign. The main aim of the paper is to shed light on the a-typical relation between multimodal metaphor and advertised product by discussing the form and function of the metaphors involved and by presenting some preliminary insights into their effects on viewers.

The form and function of the Aegean multimodal metaphors are examined from the analyst's viewpoint in relation to the generic dimensions of multimodal metaphors in advertising as put forth by Forceville (2007). It is argued that the upsetting of generic norms attested in the specific commercials, which introduces the viewer into a counterfactual, albeit wishful, world, has repercussions on the metaphor's 'verbal translation' and conceptualisation. 
In addition to discussing the Aegean multimodal metaphors from the point of view of the analyst, the paper also makes some references to the reception of the commercials in question by eight (8) Greek lay viewers of the 'bus' commercial and another six (6) lay viewers of the 'army' commercial. The involvement of lay viewers in the present qualitative study was decided in the hope that viewers' interpretation and evaluation of the commercials would enrich the analyst's own insights into the form, function and effect of the multimodal metaphors they contained. Lay viewers were between 21 and 45 years of age and professionally unrelated to academia or advertising. Their task was to watch the commercial and answer some general questions (see Appendix) concerning their understanding and appreciation of it. The reason why the two commercials were viewed by different people was to let people work out the advertised product with no previous exposure to similar commercials and thus to avoid interpretative bias.

\section{Targeting the product in advertising}

The study of multimodal metaphors in advertising is a recent endeavour (Forceville 2002, 2004, 2006; Ifantidou and Tzanne 2006; Forceville 2007; Yu 2007; Tzanne and Ifantidou 2008; Forceville and Urios-Aparisi 2009; Urios-Aparisi 2009; Hidalgo and Kraljevic 2010). Furthermore, viewers' responses to multimodal metaphors have been considered mostly in relation to metaphors appearing in political cartoons (El Refaie 2009) and visual print advertisements (see, e.g., McQuarrie and Mick 1999; Callow and Schiffman 2002; Mothersbaugh et al. 2002; van Mulken et al. 2010).

Most of the work in this area has been concerned with the various modes in which the source and target domains of such metaphors are established as well as with the relation these domains have with the advertised product. Concerning the relation between metaphor domains and product, the relevant literature discusses exclusively cases where the advertised commodity coincides with the target domain of the metaphor. In his work, Forceville (2002: 7) claims that "the product advertised (or an element metonymically associated with that product) invariably constitutes the target domain of the metaphor" or that "if the similarity between the two scenarios is perceived, the viewer cannot but understand it as a metaphor and allot target status to the domain to which the product belongs (Forcevillle 2011) [my emphasis]. The case of target domain coinciding with product makes sense as, in advertising, the source domain is of higher quality than the target. In this way, mapping the source's good features onto the target (thus creating or stressing similarities) promotes the goodness of the advertised product.

As mentioned earlier, the relevant literature, including Forceville's work, has been preoccupied exclusively with commercials where the target domain of the metaphor is indeed the advertised product. The only advertisement which can be said to illustrate the possibility of dissociating the product from the target domain is the one that promotes SHELL V-power petrol (Forceville 2004: 68-69) by 
showing fish swimming near the bottom of the sea where shells can also be seen. In this article, Forceville (2004) verbalises the metaphor in two different ways, thus reflecting, I believe, the uncertainty of the analyst (and viewer) vis-à-vis the identification of the source and the target of the metaphor. In his analysis, he presents first the FISH ARE CARS possibility, where FISH is the target and CARS the source domain of the metaphor, but soon afterwards he states the necessity to reconsider the metaphor and proposes its reversal, CARS ARE FISH, with CARS being the target and FISH the source of the metaphor. The problem with this analytical line is that it is hard for someone to find and project mappable features from fish onto cars (cars can move underwater, they are delicious when fried, etc.) in a way that constitutes a reasonable promotion of the advertised product, which, in this case, is a particular brand of petrol for cars, but not cars per se. In my view, the interpretive uncertainty suggested in this case does not relate to the identification of source and target domains of the metaphor, but to the possibility of dissociating the product from the target domain and relating it to the source domain of the first identified metaphor (FISH ARE CARS). Nowhere in his discussion does Forceville appear to consider the possibility of relating the source domain to the product, probably as a result of understanding the specific commercial in terms of his research findings up to that point, namely, that the target domain of the metaphor coincides with the product. I would like to argue that in this commercial we could construe the metaphor in terms of FISH ARE CARS and attribute to it a humorous tone by projecting onto schools of fish features of cars racing (fish rev and accelerate, they stop at the START point and dart off again, etc.). Furthermore, it could be argued that the presence of shells on the sea floor implies that, like cars filling up their tanks at a Shell petrol station, fish that swim near sea shells become just as fast, volatile and powerful.

Although the possibility of the product coinciding with the source of the metaphor is implied in some of Forceville's $(2006,2007)$ work, to the best of my knowledge, nowhere in relevant studies does it become an issue of concern. It is the aim of this paper to present and analyse the unexpected link that is created by relating the source domain of the metaphor to the advertised product, as found in the Greek TV commercials promoting the services of Aegean Airlines.

\section{The Aegean commercials}

\subsection{Commercial 1: bus driver as pilot}

The commercial begins by presenting the interior of a bus in motion. The bus driver, who is dressed casually, wears head phones and a mike and talks to the passengers for the duration of the part of the commercial which involves moving images. The driver informs the passengers about their current location and the outside temperature. He also provides information concerning their expected time of arrival and the condition of the road. 


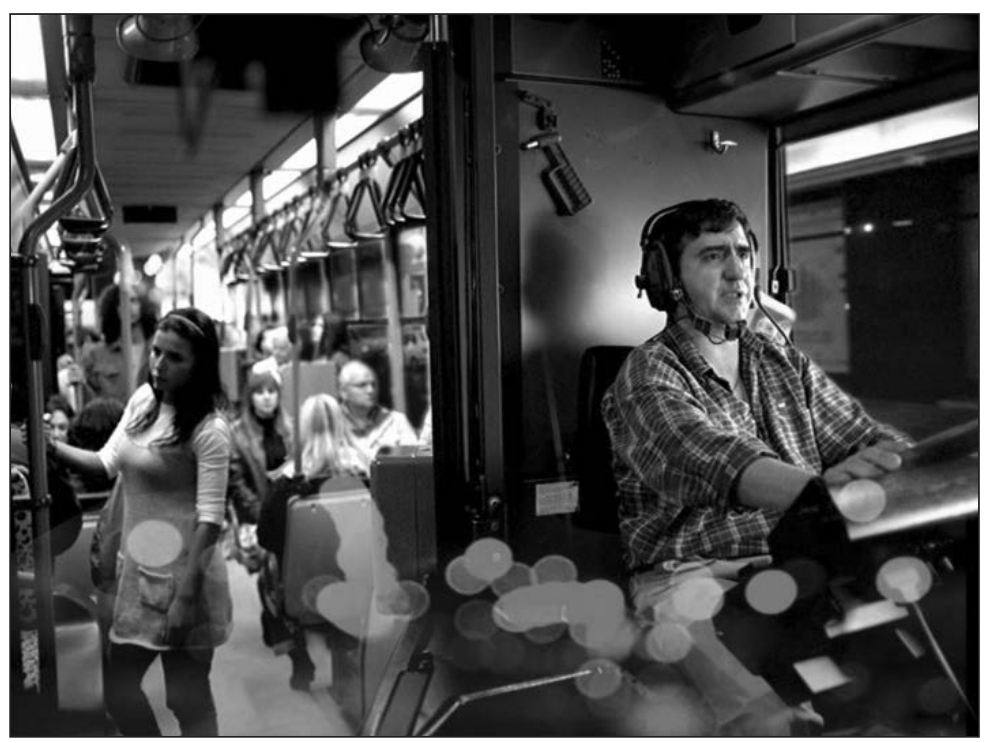

Figure 1. 'Ladies and gentlemen...': BUS DRIVER IS PILOT

While the driver is talking, the camera shifts focus onto the outside location and then zooms in on an elderly passenger who is looking out of the window with the amazed and admiring look of a tourist being guided around a city. Then the driver switches to English and utters a few phrases before the sound fades away. The script of the commercial goes as follows:

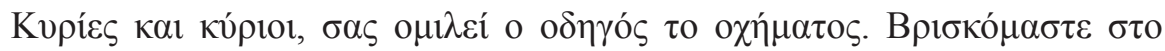

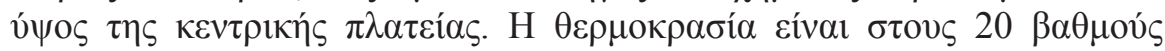

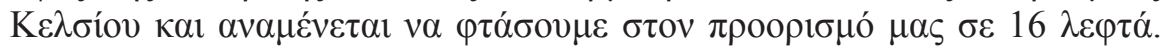

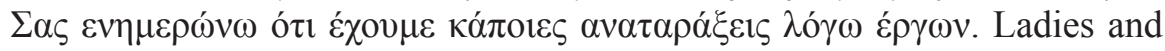
gentlemen, car driver is speaking to you...

'Ladies and gentlemen, this is the vehicle driver speaking. We are at the central square. The temperature is 20 degrees Celsius and we are expected to reach our destination in 16 minutes. I inform you that we are experiencing some turbulence because of (road) works. [in English] Ladies and gentlemen, car driver is speaking to you...'

At that point of the commercial, a still frame is presented with the written sen-

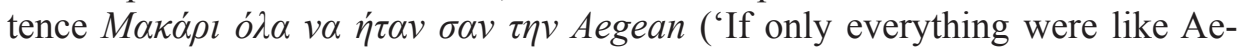
gean'). The commercial ends with another frame which presents the logo of the advertised commodity and a cartoon plane taking off. At the same time, a female voice is heard saying "Aegean - $\theta \dot{\varepsilon} \lambda \omega v \alpha \pi \varepsilon \tau \dot{\xi} \xi \omega \tau \dot{\xi} \rho \alpha$ " ("Aegean - I want to fly now'). 


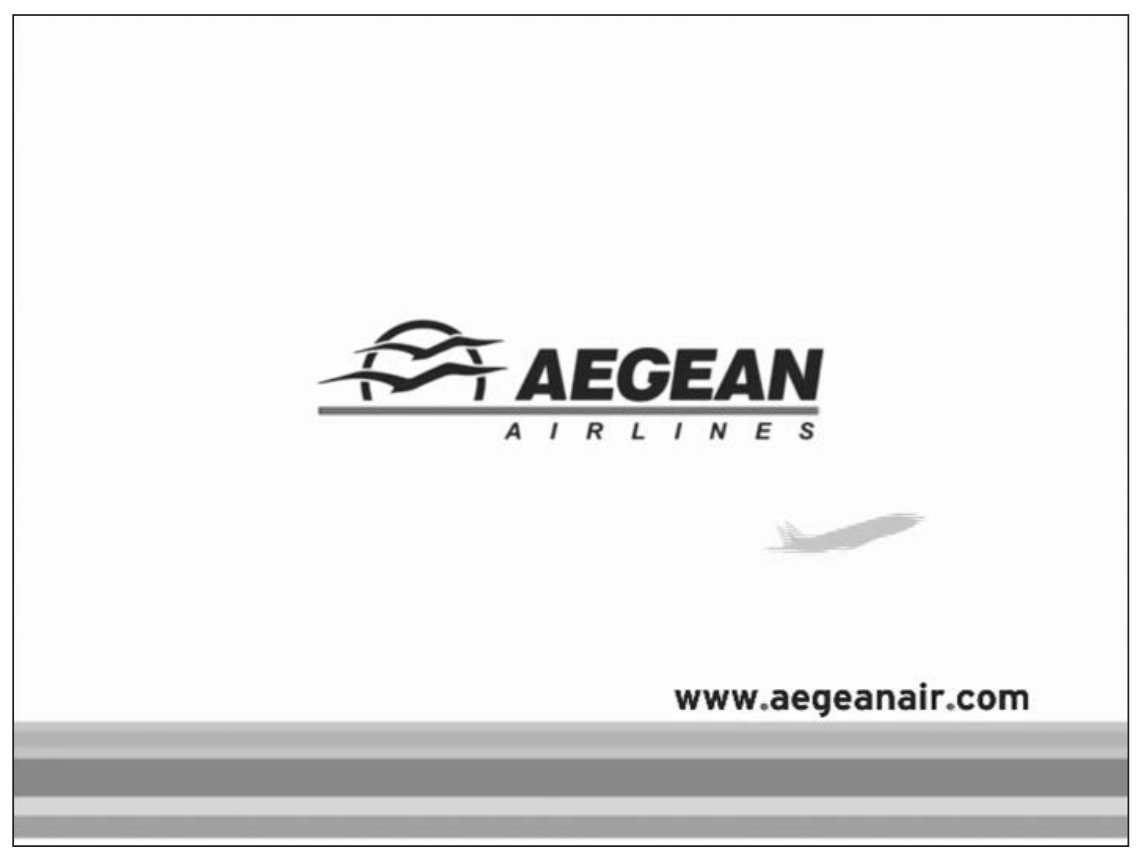

Figure 2. Aegean Airlines logo

The female voice-over suggests a young female. Her tone is passionate with sexual overtones denoting that she cannot wait to try the airliner which is so special that makes us wish everything else were as good as it is.

\subsection{Commercial 2: army caterers as air-hostesses}

The opening shot of the second commercial presents an army barracks on a rainy day and soldiers running towards a big tent, which turns out to be the Mess. The soldiers are shown to enter the tent, leave their guns by the entrance, and sit down at long tables.

After soldiers have sat on the benches provided, there is a close-up shot of the clean-shaven neck of a soldier who has just taken his helmet off. This close-up shot refers viewers to the crew cut of recruits who have just joined the army in order to do their military service. At this point, the camera zooms out on the interior of the tent and we are presented with two middle-aged women wearing white aprons who serve soldiers their meals. One of these women pushes a trolley which is full of trays with meals, while the other, rather fat, woman, walks in front of the trolley and asks the soldiers one by one about their dietary preferences before handing them their meals. 


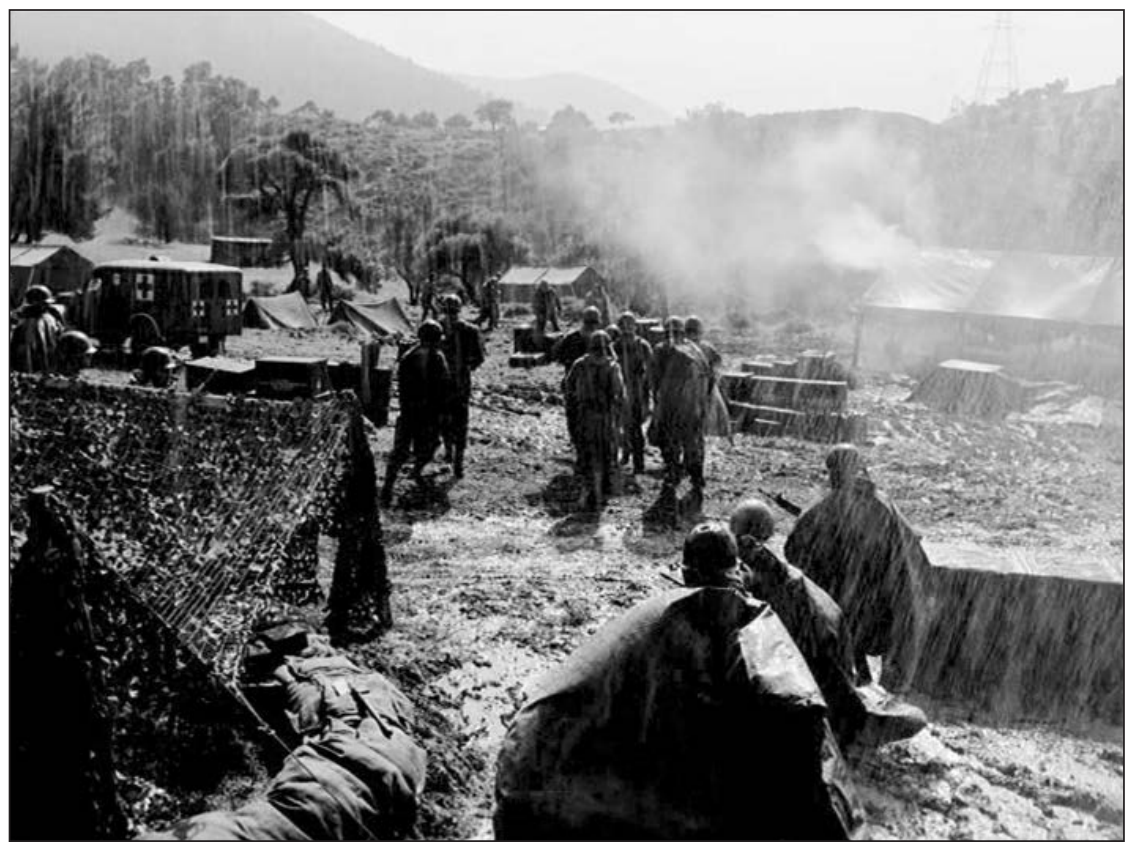

Figure 3. Setting the scene for the 'army' commercial

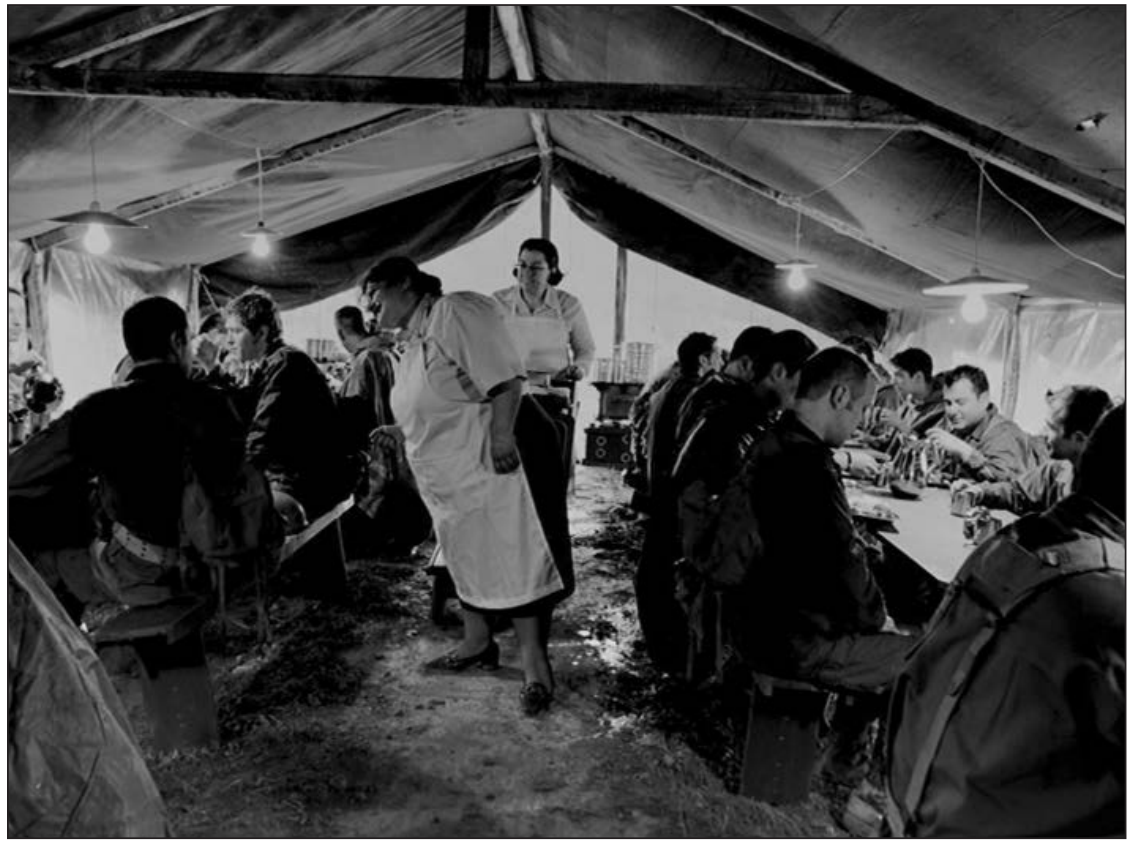

Figure 4. 'Meat of fish, please?': ARMY CATERER IS AIR HOSTESS 
The dialogue between the woman who serves and the soldiers goes as follows:

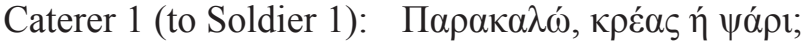
'Meat or fish, please?'

Soldier 1:

世ópl.

'Fish.'

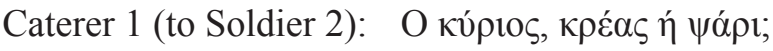

'You sir, meat or fish?'

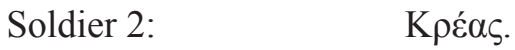

'Meat.'

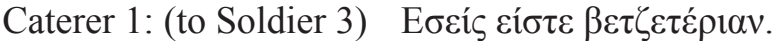

'You are vegetarian.'

Soldier 3:

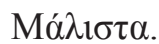

'Yes.'

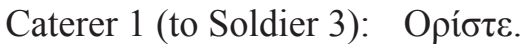

'Here you are.'

At this point of the commercial, the sound and the picture start fading out and

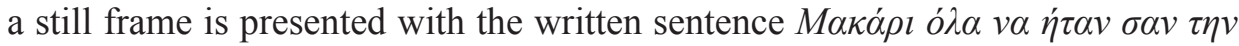
Aegean ('If only everything were like Aegean'). Similarly to the first commercial, the still frame is followed by another frame which presents the logo of the advertised commodity and a cartoon plane taking off. At the same time, a female voice-over is heard saying "Aegean - $\theta \dot{\varepsilon} \lambda \omega v \alpha \pi \varepsilon \tau \dot{\alpha} \xi \omega \tau \dot{\xi} \rho \alpha$ " ("Aegean - I want to fly now') with the same passionate tone and sexual overtones described before.

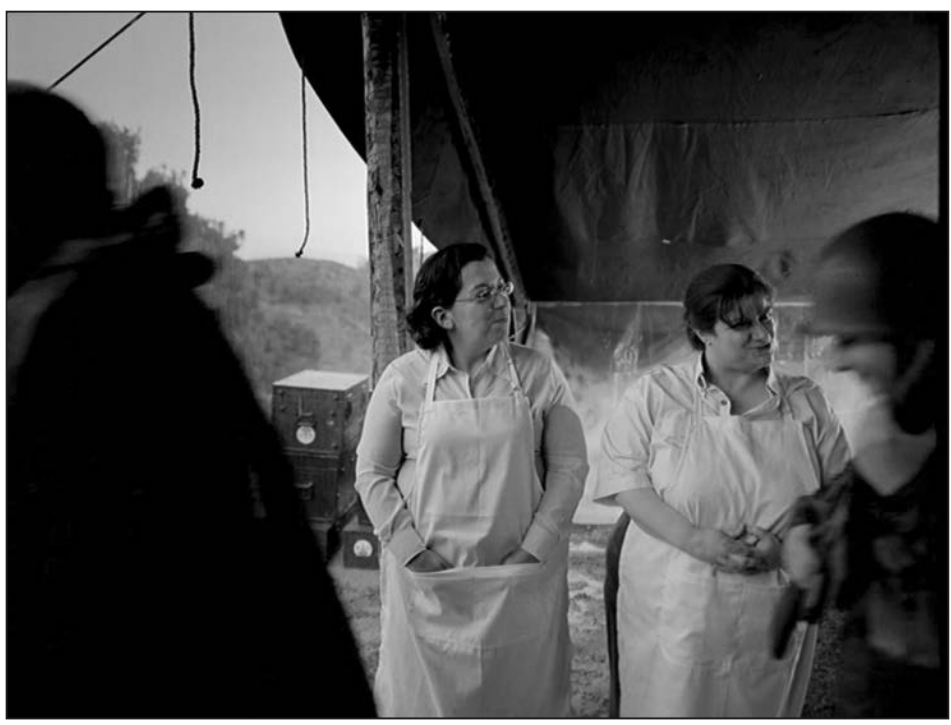

Figure 5. 'Goodbye and thank you': Addressing soldiers as passengers 
Interestingly, and unlike the first commercial, the last frame of the second commercial returns to the scene in the army barracks and presents the two women, who are now standing by the tent opening, thanking and saying goodbye to the soldiers leaving the Mess.

Caterer 2 (to soldiers): Гعı $\sigma \alpha \varsigma$.

'Goodbye'

Caterer 1 (to soldiers): $\Phi \chi \alpha \rho ı \sigma \tau o v ́ \mu \varepsilon$.

' $\mathrm{Ta}$ '

The scene depicted in the second commercial is totally incongruent with the scenario of Greek army meals, where soldiers, holding their trays, line up to be served the day's menu by other soldiers who work in the kitchen. The menu, which is known to be of low quality, is the same for everyone. The figure and the look of the woman who does the talking and the serving remind us of a Greek canteen or school caterer; her talk, however, refers us clearly to the discourse of an air-hostess, in terms of both lexical items and polite tone of voice. The last scene of the commercial, in particular, can be paralleled with the disembarkation scene from an airplane, when air hostesses standing by the exit door say goodbye to the passengers and thank them for having travelled with the specific airline.

In the sections that follow, I will discuss the identified metaphors in terms of the generic features of multimodal metaphors in commercials, as outlined in Forceville (2007). I will argue that the metaphors involved in the two commercials are relatively easy to construe, as source and target domains are cued in equally noticeable ways and source is known to be of higher value than the target (plane services are better than bus services, in-flight meals are better than army meals). More specifically, these commercials follow, to an extent, the norms of the advertising genre, in that the source of the metaphor they present is indeed better than the target, thus making it possible to select and map good features from the source onto the target domain. However, the advertised product is not so easy to identify as it is not explicitly shown in the commercials until the very end (still frame with logo and frame with cartoon plane). Additionally, it will be shown that these commercials defeat viewers' genre-specific expectations by relating the product with the source and not the target domain of the metaphor.

\section{Do these commercials contain metaphors?}

The initial interpretation of the Aegean commercials is that they both contain metaphors that invite their recipients to find similarities and differences between two entities that have never been related to each other before. These metaphors have been called 'creative metaphors' by Black (1993) who argues that they are intriguing in that they may point to a whole new way of thinking. In other words, 
they are metaphors for the identification of which it is not possible to draw on shared ready-made categorisations and stereotypes. These metaphors have also been termed 'new metaphors' (Lakoff and Johnson 1980: 139ff.), or 'one-shot metaphors' (Lakoff and Johnson 1989, in Forceville 2005: 268) in order to be distinguished from conventionalized metaphors. Creative or new metaphors are very common in the genre of advertising, as new ways must be found all the time to arouse and maintain viewers' interest, "to grab attention through surprise" (Cook 1992:11).

Metaphors, in Black's (1993) terms, involve a primary subject (target) and a secondary subject (source) and any metaphorical text works by projecting upon the primary subject selected properties of the secondary subject. Drawing on Black's theory, Forceville (1996: 108) poses three questions as criteria for the identification of metaphors. In order for a phenomenon to qualify as a metaphor, there have to be clear and specific answers to three questions:

(1) What are its two domains?

(2) What is its target domain, and what its source domain?

(3) Which feature or (structured) cluster of features can/must be mapped from source to target?

In what follows, I will attempt to answer the above questions by retracing the steps leading to the interpretation of the two Aegean commercials. The first question can be answered quite easily, though verbalising and connecting the two domains is not without problems. Verbalising a visual metaphor has repeatedly been discussed as a tricky issue, in that different ways of verbalization may lead to different interpretations of the metaphor (Forceville 2007). Beginning with the 'bus' metaphor, my first verbalization of the two domains as BUS DRIVER / PILOT was replaced by the more general BUS TRAVEL / AIR TRAVEL to which bus driver and pilot point metonymically ${ }^{2}$. By the same token I verbalised the two domains in the 'army' metaphor as AIR TRAVEL and ARMY. At this stage of the analysis, given the salient verbal and visual cues provided by the commercials, verbalising the two domains of the metaphors involved seems quite straightforward, but when it comes to deciding on target and source domains on the basis of this verbalization, some interpretive issues arise.

As the 'bus' commercial starts unfolding, and before getting to the last two frames, where the advertised product is presented, two possible interpretations of the metaphor suggest themselves: according to the first one, the metaphor can be verbalised as AIR TRAVEL IS BUS TRAVEL ${ }^{3}$, where AIR TRAVEL is the target of the metaphor and BUS TRAVEL the source. According to Forceville's (2007: 29-30) third generic dimension of multimodal metaphors in advertising, "the features mapped from source to target are always positive ones - unless the target is not the product advertised but a rival brand to be disparaged". Given that, in this case, it is difficult to find mappable features in the form of qualities that are better in buses than in planes, this interpretive possibility has to be rejected, unless 
we perceive this commercial as one ridiculing airliners, which justifies the lower quality product being the source of the metaphor. However, since an obvious effort is observed to present an improved, almost ideal, picture of bus services in Greece, we have to acknowledge that bus services are here presented to rub shoulders with a better entity, airline services, which rules out the possibility of this commercial aiming to ridicule airliners.

The second interpretative possibility, according to which BUS TRAVEL IS AIR TRAVEL, places BUS TRAVEL in the target domain and AIR TRAVEL in the source domain of the metaphor. In this case, to claim that Greek buses are as good as planes constitutes as false a statement as the one previously considered. It is a claim though that agrees with the aforementioned generic dimension of multimodal metaphors in advertising, namely that the source of the metaphor is an entity that exhibits better qualities than the target. In other words, in the particular genre, the good qualities of the source are mapped onto the target, so we understand that some good qualities of air travel are mapped onto bus travel; in particular, hearing the driver inform the passengers about the route, the weather, the temperature, time of arrival and journey conditions, we can perhaps verbalise this good quality as "informing passengers about journey/travel", which we (Greek people) know to be good in air travel, but bad, almost non-existent, in bus travel. This may make viewers conclude that the target of the metaphor is BUS TRAVEL, upon which the goodness of the source (with respect to providing information to passengers) is mapped. And as the target of the metaphor usually coincides with the advertised product (Forceville, 2007), viewers are also likely to interpret the commercial (at least initially) as one which promotes bus services in Greece. This interpretative possibility proved to be quite strong when half of

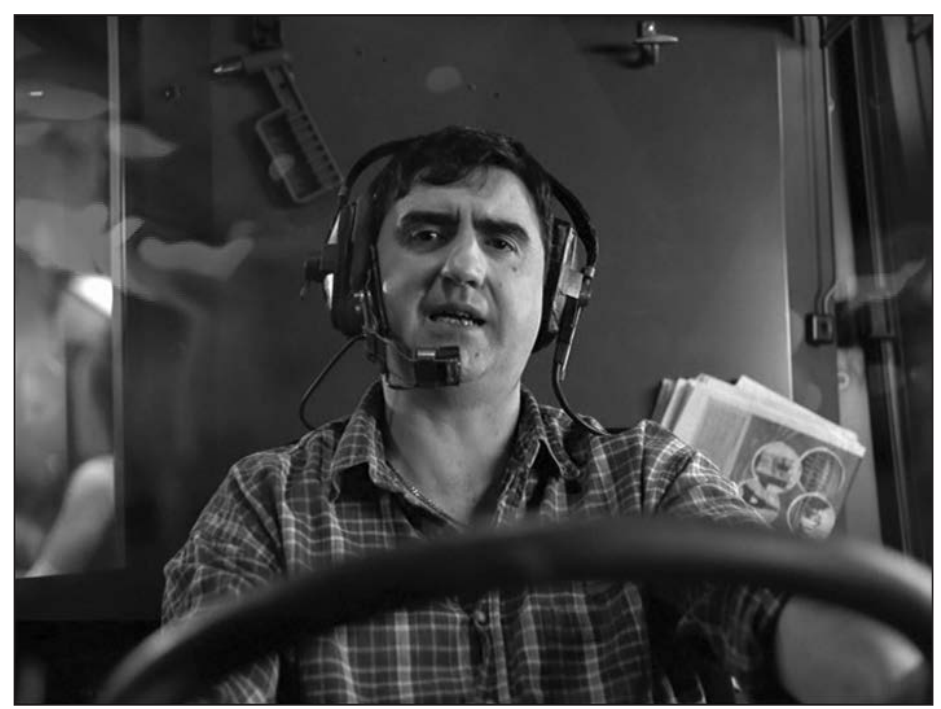

Figure 6. Humourous depiction of bus driver as pilot 
the lay viewers of the 'bus' commercial said that at some point they did consider bus services to be the advertised product. Naturally, a large-scale empirical study is needed in order to confirm the strength of this possibility.

On the other hand, trying to make sense of the metaphor BUS TRAVEL IS AIR TRAVEL in terms of informing passengers is particularly difficult, as Greek people know that bus drivers hardly ever speak to passengers, even when asked to provide information. In general terms, the viewers of this commercial who admitted to having initially considered bus services as the product reported having had great difficulty in finding a single thing that Greek bus transport could advertise as being good. The visual channel emphasizes the impossibility of BUS TRAVEL IS AIR TRAVEL, too: it is as unlikely to see a Greek bus driver wear head phones and mike, as it is to hear them give information to passengers. In short, the above format does not hold true for Greek bus services, and this is most probably why the metaphor is viewed as one that depicts a surreal situation and creates humour.

Crucial to our understanding of the metaphor and interpretation of this commercial is that the bus driver is here depicted as a stereotypical Greek bus driver with his checked shirt and suggested low educational level: the way he pronounces the Greek word for 'minutes' ([lefta] instead of [lepta]) indicates that he is not highly educated, something which is also suggested by the mistake he makes in the English part of his announcement (car instead of vehicle driver in "car driver is speaking to you') and his heavy Greek accent. Seeing this stereotypical Greek bus driver with head phones and mike and hearing him make his announcement

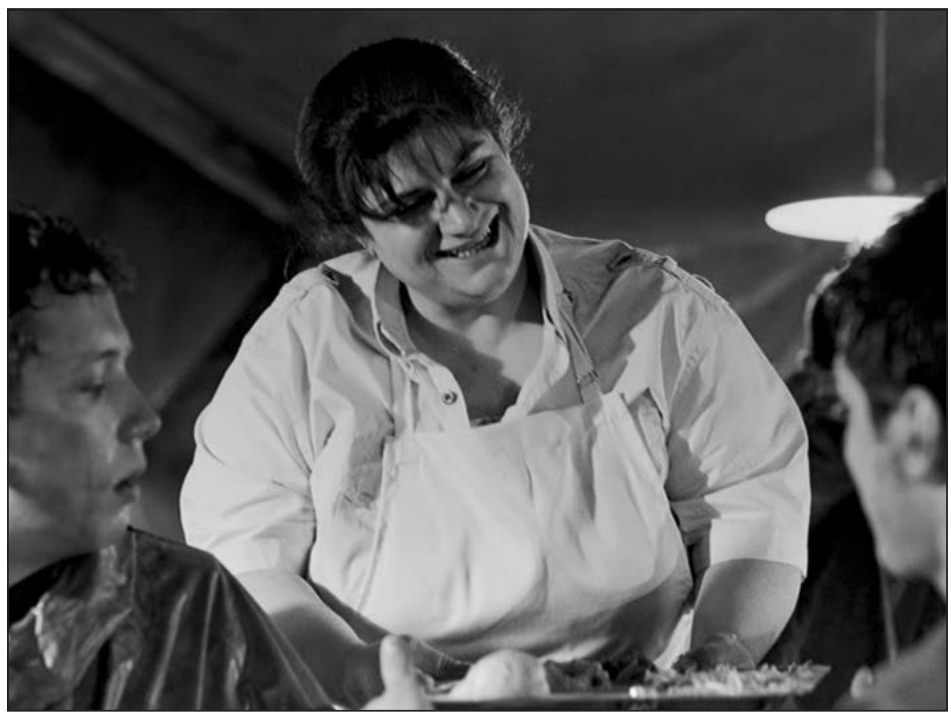

Figure 7. Humorous depiction of army caterer as air hostess 
creates a totally incongruous picture whose main aim is most probably to create humour. Indeed, all lay viewers said that the driver was funny on account of the way he looked and of what he said. A similar picture is created for the army caterers, too, especially for the one who serves the soldiers, as, first of all, her appearance seems to be a parody of the stereotype of beautiful, slim and elegant air hostesses.

Moreover, similarly to the bus driver, she also appears not to be highly educated. In particular, in the last scene of the commercial she is shown to thank the soldiers by saying [fharistume] instead of the standard [efharistume], which points, among others, to a not highly educated person. All lay viewers of this commercial commented on the figure and the discourse of this woman as being hilarious ${ }^{4}$.

Concerning the 'army' commercial, the interpretative possibility of AIR TRAVEL IS ARMY has to be ruled out at once, as life in the army is never discussed in any positive features that could be mapped onto the other entity, namely air travel. What seems to be a more plausible interpretation, at this stage, is the alternative ARMY IS AIR TRAVEL, where we can assume that the army has taken measures to improve the quality of the meals it offers so that they resemble the good quality and service of in-flight meals. However, what remains unfathomable is the reason why the Greek army would want to advertise itself on these grounds. In fact, it should be noted that military service, which is compulsory in Greece, has never been advertised before in any way, nor does it have any reason whatsoever to appear as a product advertised on television. Therefore, although we recognise the superior quality of in-flight meals over army meals, we remain puzzled about the advertised product of this commercial.

With respect to identifying the source and target domain of a metaphor, the issue of directionality is a central one to consider. In his studies, Carroll (1994 and 1996) addresses the question whether target and source domain are reversible and argues that the irreversibility that can be identified in all linguistic and in many pictorial metaphors holds for many film metaphors as well. However, he argues that unidirectionality and irreversibility "might not be an essential feature of film metaphors" and adds that film metaphors invite the viewer to test "whether the putative target domains and source domains can be flipped" (1996: 220-221). This invitation to testing seems also to be the case with the Aegean commercials, given that the advertised product and its good qualities are not clear from the start; in addition, our initial interpretations about bus travel or the army being as good as air travel are difficult to sustain for long for reasons of the culturallyrelated counterfactuality already discussed.

In my view, examining whether source and target domain can be flipped is a necessary step towards interpreting the particular commercial, but it does not argue in favour of the metaphor's reversibility. In fact, I agree with Forceville (2002: 7) when he claims that "prototypical metaphors of all kinds and occurring in all media have clearly distinguishable target and source domains, which in a given context cannot be reversed". In this case, the goodness of air travel 
compared with bus travel is indisputable and this cannot be easily reversed in the minds of the viewers, nor can the high quality of in-flight meals be questioned when compared with low-quality army meals.

The answer to Forceville's (1996: 108) second question is thus clear within the realm of advertising: air travel is the source in both metaphors, as, in advertising, the source must be of higher value than the target (bus travel, the army). Finally, concerning Forceville's (1996: 108) third question, some of the features that can be mapped onto the target domain of 'bus travel' are informative, punctual, and reliable. Additionally, some of the positive features that can be mapped onto the target domain of 'army' are menu variety, high meal quality and polite behaviour on the part of the caterers. By foregrounding the desirable and positive aspects of the source domain, the advertisers probably make a tongue-in-cheek statement, telling the audience that bus travel in Greece/Athens is as good as air travel and that army meals are as good as in-flight meals. The fact that there are no such similarities between the compared entities does not affect the construal of the metaphor, but it creates humour, although it most probably causes problems to the viewers concerning the identification of the advertised product. Half of the viewers of the 'bus' commercial reported to have difficulty identifying the product at the beginning, but only one viewer of the 'army' commercial reported some initial difficulty, which can be explained on the basis of real world knowledge that does not allow viewers to sustain prolonged uncertainty concerning the identification of the product in this case.

At this point I would like to argue that the fact that our interpretation of the metaphors still leaves us with questions concerning the point of the commercials and the product they advertise does not relate to our construal of the specific metaphors, but to the genre-related deviation these commercials involve, namely the unusual relation of the source domain of this metaphor to the product advertised, something we come to realise only upon viewing the last two shots of the commercial. The interpretative problems encountered so far and the uncertainty clouding over the identification of the product advertised are resolved when the logo of the ad appears ("if only everything were like us"), upon which we realise that the unreal situation depicted through the hybrid metaphor in fact aimed to promote Aegean airlines.

The main interpretative difficulties associated with these commercials stem from the fact that, although the two domains of the metaphor are in accordance with the conventions of the genre (good qualities of the source domain are mapped onto the target domain), contrary to viewers' genre-related expectations concerning the relation of metaphor to the product, the target domain of the metaphors IS NOT the advertised commodity. It is this genre-related deviation that has probably led lay viewers to characterise the commercials as 'clever', 'original' and 'successful'. 


\section{Cuing the Aegean multimodal metaphors}

In this section, I examine the role of visual and verbal cues in the construction of the source and target domains of the metaphor involved and attempt to place within multimodal theory the fact that the advertised product is suggested, but not clearly depicted in the commercial, until the very end, when it is cued both visually and verbally.

According to Forceville (2004: 66), metaphors "whose target and source domains are predominantly or entirely presented in two or more different modes are "multimodal metaphors"'. As he (2005) rightly observes, in multimodal metaphors, target and source domains may be cued and identified in a non-linear, complex manner. In particular, he (2005: 274-5) argues that in metaphors in moving images

(1) target and source need not be presented at the same moment; (2) a domain (target or source) can be cued sonically as well as pictorially and/or verbally; (3) moving images allow for the establishment of similarity via camera angles and frames as well as via camera movements: two phenomena can be saliently emphasised using any of these stylistic options to create, or help create, metaphoric similarity.

The metaphors examined here are multimodal metaphors, as the two domains involved are cued both visually and aurally. The two domains are cued simultaneously in a salient way (here we deal with an 'explicitly signaled metaphor' in Forceville's (2002: 11) terms). Additionally, these metaphors are 'hybrid' metaphors (Forceville 2007: 17), as "parts of both terms are pictorially represented, resulting in a hybrid phenomenon perceived as a single gestalt". In this case, viewers are confronted with a "violent fusion" of source and target (Forceville 1996: 143) which van Mulken et al. (2010: 3420) consider to be more deviant than merely juxtaposing the source and target elements and not blending them in a single unreal entity.

In the 'bus' commercial, the domain of BUS TRAVEL is mainly cued visually (bus, bus driver, streets, buildings), but also aurally, as some of the words used in the driver's announcement refer directly to this domain ('the driver of the vehicle', 'central square', 'road works'). On the other hand, the domain of AIR TRAVEL is mainly presented visually (the bus driver is wearing the head gear of a pilot) but also verbally ('turbulence'). Moreover, the announcement has the structure of an in-flight announcement, while in places it is fleshed out by vocabulary that relates to bus travel. In this respect, the verbal part of the commercial is also a hybrid, similar to its visual counterpart. In the particular commercial there is no music, but sound that comes from driving the bus on a bumpy road. This non-verbal sound also cues the target domain of the metaphor.

In the 'army' commercial, ARMY is mainly cued visually (soldiers in full armour, an army barracks, tent serving as 'the mess'), but also sonically (sound 
of soldiers' running as part of their daily training, male voice shouting orders). On the other hand, the domain of AIR TRAVEL is presented visually through the movements, body posture and equipment of the caterers (women with white aprons pushing a trolley with meals on trays and serving people, later on standing by the tent exit thanking and saying goodbye to the people they had served before), but mainly verbally, with the discourse of one of the caterers being identical to the discourse of air hostesses. At this point, it is interesting to mention that the verbal part of the metaphor in this commercial is not a blend of army and air travel discourse, but belongs exclusively to the domain of AIR TRAVEL. An interesting detail in the script is that the caterer seems to know in advance who is vegetarian, as she addresses Soldier 3 with a request for confirmation ('You are vegetarian') rather than with a request for information ('Are you vegetarian?'). This refers the viewer to in-flight meals, where air-hostesses are given in advance the seat numbers of the passengers who have ordered a vegetarian meal. In this way, the viewer is invited to find similarities between the army caterer and an air hostess serving meals.

Finally, similarly to the 'bus' commercial, there is no music in this commercial, but sounds that relate to life in the army, which cue the target domain of the metaphor.

Concludingly, the source domain of AIR TRAVEL is primarily cued verbally in both commercials, whereas the target domains of BUS TRAVEL and ARMY are primarily cued visually, which is in line with Forceville's claim (2011: 8) that "if one of the domains is exclusively cued visually, and the other exclusively verbally, it tends to be the target that is visually, and the source that is verbally cued".

The source domain of the metaphor is explicitly cued through the visual channel in the last two frames of the commercial, with the still frame "If only everything were like Aegean" and the last cartoon-like shot and the female voice-over saying "Aegean: I want to fly now". It is not until these last shots, that the viewer is able to identify the product with certainty, and at the same time realise that, contrary to his/her (genre-related) expectations, in the 'bus' commercial, it is not bus travel (the target domain of the metaphor), but air travel (the source domain), which is advertised. This means that at this point the viewer will have to reconsider her/his interpretation in order to make sense of the commercial in this new light. This interpretative uncertainty does not seem to arise or be sustained even for a very short time in the case of the 'army' commercial, where, with the help of world background knowledge, the possibility of watching a commercial that advertises the army has almost certainly been ruled out by viewers. In fact, none of the lay viewers reported to believe that this was an advertisement for the army or military service (however, one did say that he entertained this thought for a few seconds at the beginning), as opposed to some viewers of the 'bus' commercial, who said that they initially believed it to be an advertisement for Greek bus services.

According to Forceville (2011: 8), "if target coincides with product advertised, at some stage or other - but at the very last in the final shot of the commercial - it 
will also be labelled verbally". The analysis of the two Aegean commercials has shown that what Forceville (2011) states in relation to cuing source and target also holds true when the advertised product coincides with the source domain of the metaphor. In other words, although in the commercial examined it is the source and not the target domain of the metaphor which coincides with the product, the advertised product is labelled both verbally and visually in the last two shots of the commercial, where the logo of the airliner, one that hovers between verbal and visual, is also shown. Therefore, it seems that commercials containing multimodal metaphors follow the general tendency of showing the advertised product last, so that it stays in the mind of the viewers, irrespective of whether the product coincides with the source or the target domain of the metaphor.

In cases where the target is the product, cuing the source before target and product are identified arouses and maintains viewers' interest in commercials (Forceville 2007). In the commercials examined, the advertising company may have presented source and target simultaneously, but they have found a different way of maintaining viewers' attention and of promoting the product in a clever and original way: they have intended the source to be the product, which may initially confuse and finally surprise viewers.

Furthermore, the fact that viewers' interpretation of the metaphor is greatly facilitated by visual and aural (verbal) means counterbalances, in my view, the upsetting of expectations brought about by relating the source of the metaphor to the advertised commodity and presenting viewers with a clear case of counterfactuality.

\section{Verbalising the relation of source and target domains in the Aegean metaphor}

As Forceville (2007: 27) puts it, "the A IS B format underlies all metaphors on a conceptual level. However, it is only in language that the surface manifestation and the conceptual structure can be made to resemble each other". According to him (2007: 27), "even in purely verbal metaphors, the conceptual A IS B level is an inferred 'verbal translation' from the surface level". At this point, in order for the verbal manifestations of the multimodal metaphors discussed above to approach their conceptual structure, a careful investigation and reconsideration of their verbalizations is deemed necessary.

Forceville and Urios-Aparisi (2009: 13) contend that non-verbal and multimodal metaphors such as the one analysed here "are not, or not as clearly, expressible in their verbal manifestations". The authors (2009: 13) consider the 'translation' of these metaphors into verbal ones to be "an approximation at best". More importantly, Forceville (2005: 269) criticizes the A IS B format for suggesting a state of affairs rather than a dynamic situation, which is incompatible with the fact that "it is often certain processes or actions in the source domain, considered (un)desirable and/or (in)appropriate, that are supposed to be mapped onto 
the target domain". In similar vein, Forceville and Urios-Aparisi (2009) criticize the format A IS B for disguising the dynamic nature of metaphor and thus for being unable to render verbally the scenarios or mini-narratives involved in many metaphors. They (2009: 11) propose a change from the paradigmatic formula 'NOUN A IS NOUN B' to 'A-ING IS B-ING' "since metaphor is always metaphor in action".

Whereas the above criticisms are largely concerned with the verbalization of the domains of a metaphor, the difficulty with following the traditional format 'A IS B' in the verbalization of the Aegean metaphors is of a different nature. In this case, the difficulty stems from the fact that expressing the relation between the source and the target domain of a multimodal metaphor is not straightforward, as "the nature of the metaphorical "is" is non-verbal" (Forceville, 2007: 26). It is my contention that the difficulty with following the 'A IS B' format lies in adopting the modality of certainty ('IS') of the copula verb involved in the relational process through which the qualities of NOUN B are attributed to NOUN A. More specifically, in the case of the Aegean commercials, the problem that arises relates to the fact that this type of metaphor is one that equates two elements that cannot co-occur in reality, and, therefore, depicts an unreal, counterfactual situation. In this case, the problem with the initial construal of the metaphor (BUS TRAVEL IS AIR TRAVEL) remains and, as the reverse of the metaphor is not acceptable either (AIR TRAVEL IS BUS TRAVEL), in order to 'verbally translate' this particular type of metaphor, I would like to suggest a grammatical change in the way the two domains are linked. In particular, I would like to suggest a change in the modality used in the traditional format from one expressing categorical truth (IS) to one expressing probability (COULD BE) and a hypothetical, rather than an actual, state of affairs. This grammatical change concerns not only the format of the metaphor, but also the concept of it, making it one that relates to the realm of the currently-unreal, but possible-in-the-future. Interestingly, one male viewer of the 'army' commercial expressed his wish that army meals were as good as the meals shown in the commercial, and two of the people who viewed the 'bus' commercial said that having buses as punctual and informative as airplanes was "wishful thinking", which refers to the conceptual rather than the surface level of the metaphor. Thus I propose the format 'A COULD BE B' for this type of metaphor and render verbally the point of the first commercial as BUS TRAVEL COULD BE (as good as) AIR TRAVEL, and the point of the second commercial as ARMY COULD BE (as good as) AIR TRAVEL.

In agreement with Forceville's (2007) claim that surface verbalization relates to conceptualization of a metaphor, I assume that the way we conceptualise the particular metaphors requires a different kind of language equation, one that can capture the point of the commercials which invites us to a possible, hypothetical world where bus services and army meals would improve if the goodness of airline services, the advertised product, could spill over them. As pointed out above, some of the people who saw these commercials hinted at the conceptualization of this possible equation. 


\section{Concluding remarks and possibilities for further research}

This study was concerned with two commercials from the advertising campaign of a Greek airliner, Aegean Airlines. A thorough analysis of the two commercials showed that they present two types of deviation, a 'metaphor-related' deviation deriving from the fact that they involve multimodal hybrid metaphors, and a 'genre-related' deviation, in that the advertised commodity coincides with the source and not the target of the metaphor.

In more specific terms, first of all, it was established that the two commercials involve metaphors, the domains of which are in accordance with the conventions of the genre of advertising: the good qualities of the source domain are mapped onto the target domain of the metaphor. However, contrary to viewers' genre-related expectations concerning the relation of domains of metaphor to the product, it was found that the target domain of these metaphors is not the advertised commodity. This 'genre-related' type of deviation was found to be greatly appreciated by the lay viewers of the study, as the majority of them reported to be pleasantly surprised by the commercials.

Another finding of this study was that the source domain, which is the same in both commercials, was primarily cued verbally, whereas the target domains were cued mainly through the visual mode. This confirms previous claims relating the source domain of metaphors to the verbal mode of communication and the target domain to the visual.

Furthermore, it was found that, similarly to what is observed in commercials where the target domain coincides with the advertised product, in the two Aegean commercials where the product coincides with the source domain, the advertised commodity was presented visually and labeled verbally in the last frames. Therefore, it seems that commercials containing multimodal metaphors follow the general tendency of showing the advertised product last, so that it stays in the mind of the viewers, irrespective of whether the product coincides with the source or the target domain of the metaphor.

Finally, it was found that the identification of source and target domains as well as the verbalization of the two Aegean metaphors were somehow problematic, most probably because of the fact that surreal, counterfactual situations were depicted in the commercials. Making these situations resemble the way the two metaphors can be translated into language dictated a change from the 'A IS B' format of metaphor verbalizations to 'A COULD BE B', in order for it to accommodate cases of hypothetical and not actual resemblance between the entities compared through the metaphor.

A feature of both commercials that was greatly appreciated by their viewers was the humour that was created by the multimodal metaphors involved. It is clear that the aim of the commercials examined in this paper is not limited to persuading prospective customers to travel with Aegean Airlines: these commercials aim to also entertain viewers by presenting them with humorous characters (bus driver / army caterers) and situations (a Greek bus driver talks like a pilot / army 
caterers who serve meals to soldiers look like school canteen caterers and talk like air hostesses).

Metaphor- and genre-related deviation presented lay viewers with difficulties in understanding the point of the commercial and identifying the product. At the same time, however, the humorous situation depicted must have motivated them to expend extra effort in order to interpret the deviant features of the commercial. It is this humorous effect that most probably makes viewers feel that their additional efforts to establish relevance are worthwhile. From these preliminary insights into the creation and effect of humour in television commercials, it becomes obvious that the creation of multimodal humour and the effect it has on viewers of commercials is certainly an interesting issue which merits thorough investigation and extensive discussion in future research.

The commercials discussed in this study exploit well-known stereotypical figures in new roles in order to create humour. In this case, interpreting the situation as humorous appears to be a socio-cultural matter, as Greek viewers recognise the impossibility of the scenes they are presented with and detect the humorous effect created by them. It is doubtful that these commercials would achieve the same effects in a culture where, for example, bus drivers look and behave differently from Greek drivers, and where bus services are reliable and punctual. Indeed, asking viewers from other (than Greek) cultures to interpret and evaluate the two Aegean commercials suggests itself as another interesting possibility for future research.

\section{Notes}

1 When the Public Relations office of Aegean Airlines granted me permission to do research on the specific advertising campaign, they sent me a DVD with the first two commercials, named 'Bus' and 'Army'.

2 For the interaction between multimodal metaphor and metonymy, see Urios-Aparisi (2009) and Hidalgo and Kraljevic (2010).

3 The modality of the copula verb 'to be' in this verbalization is later discussed as problematic and reconsidered (see section 6).

4 Humour in these commercials is of a multimodal nature, in that it is created through the visual and verbal mode in combination (cf. Tsakona 2009). Examining the multimodal humour of these commercials lies beyond the scope of this paper.

\section{Appendix}

1. Have you seen this commercial before?

2. Did you like the commercial? Give reasons.

3. Did you have difficulty identifying the product from the start?

4. Did you notice anything unusual about the bus driver / caterer?

5. What is the point of the commercial concerning the advertised product?

6. How would you characterise this commercial? Give reasons. 


\section{Acknowledgements}

I am grateful to Charles Forceville for his valuable comments on the paper presentation upon which this article is based. I would also like to thank Aegean Airlines and Upset $\subset$ for granting me permission to conduct research on the two commercials discussed in this study. Finally, I would like to thank the lay viewers of the Aegean commercials for the eager participation in the study.

\section{References}

Black, Max (1993) “More about metaphor". In: Ortony, Andrew (ed.) Metaphor and Thought, $2^{\text {nd }}$ ed. Cambridge University Press, Cambridge, 19-41.

Callow, Michael, Schiffman, Leon (2002) 'Implicit meaning in visual print advertisements: a crosscultural examination of the contextual communication effect". International Journal of Advertising 21, 259-277.

Carroll, Noel (1994) "Visual metaphor". In: Hintikka, Jaakko (ed.) Aspects of Metaphor. Kluwer, Dordrecht, 189-218.

Carroll, Noel (1996) “A note on film metaphor”. In: Carroll, Noel (ed.) Theorising the Moving Image. Cambridge University Press, Cambridge, 212-223.

Cook, Guy (1992) The Discourse of Advertising. Routledge, London and New York.

El Refaie, Elizabeth (2009) "Metaphor in political cartoons: exploring audience responses". In: Forceville, Charles and Eduardo Urios-Aparisi (eds.) Multimodal Metaphor. Mouton de Gruyter, Berlin and New York, 173-196.

Forceville, Charles (1996) Pictorial metaphor in advertising. Routledge, London and New York.

Forceville, Charles (2002) "The identification of target and source in pictorial metaphors". Journal of Pragmatics 34, 1-14.

Forceville, Charles (2004) "The role of non-verbal sound and music in multimodal metaphor". In: Aertsen, Henk, Mike Hannay, and Rod Lyall (eds.) Words in their Places: A Festschrift for J. Lachlan Mackenzie. Faculty of Arts, VU Amsterdam, Amsterdam, 65-78.

Forceville, Charles (2005) "Cognitive linguistics and multimodal metaphor". In: Sachs Hombach, Klaus (ed.) Bildwissenschaft: Zwischen Reflektion und Anwendung. Von Halem, Cologne, 264284.

Forceville, Charles (2006) "Non-verbal and multimodal metaphor in a cognitivist framework: agendas for research". In: Kristiansen, Gitte, Michel Achard, René Dirven, Francisco Ruiz de Mendoza Ibàňez (eds.) Cognitive Linguistics: Current Applications and Future Perspectives. Mouton de Gruyter, Berlin and New York, 379-402.

Forceville, Charles (2007) "Multimodal metaphor in ten Dutch TV commercials". The Public Journal of Semiotics 1 (1), 15-34.

Forceville Charles (2011) "A Course in Pictorial and Multimodal Metaphor: Lecture 4, Pictorial and multimodal metaphors in commercials". Retrieved February 6, 2011 from http://projects. chass.utoronto.ca/semiotics/cyber/cforceville4.pdf.

Forceville, Charles, Urios Aparisi, Eduardo (2009) “Introduction”. In: Forceville, Charles and Eduardo Urios Aparisi (eds.) Multimodal Metaphor. Mouton de Gruyter, Berlin and New York, $3-17$.

Hidalgo, Laura, Kraljevic, Blanca (2010) "Pragmatic inferencing and interaction between multimodal metaphor and metonymy in advertising discourse". Paper presented at the $4^{\text {th }}$ CLAN Conference, Madrid 15-17 November 2010.

Ifantidou, Elly and Angeliki Tzanne (2006) "Multimodality and relevance in the Athens 2004 Olympic Games televised promotion”. In: Martinez, J. M. and Francisco Yus (eds.) Revista Alicantina de Estudios Ingleses 19, 191-210. 
Lakoff, George and Mark Johnson (1980) Metaphors We Live By. University of Chicago Press, Chicago, Il.

McQuarrie, Edward F., and David Glen Mick (1999) "Visual rhetoric in advertising: text interpretive, experimental and reader-response analysis". Journal of Consumer Research 26, 37-53.

Mothersbaugh, David L., Bruce A. Huhmann and George R. Franke (2002) "Combinatory and separative effects of rhetorical figures on consumers effort and focus in ad processing". Journal of Consumer Research 28, 589-602.

Myers, Greg (1994) Words in Ads. Arnold, London.

Tsakona, Villy (2009) "Language and image interaction in cartoons: towards a multimodal theory of humor". Journal of Pragmatics 41 (6), 1171-1188.

Tzanne, Angeliki and Elly Ifantidou (2008) "Joy in advertising the Athens 2004 Olympic Games on Greek television". In: Lascaratou, Chryssoula, Anna Despotopoulou and Elly Ifantidou (eds.) Reconstructing Pain and Joy: Linguistic, Literary, and Cultural Perspectives. Cambridge Scholars Publishing, Newcastle-upon-Tyne, 431-449.

Urios Aparisi, Eduardo (2009) "Interaction of multimodal metaphor and metonymy in TV commercials: four case studies". In: Forceville, Charles and Eduardo Urios Aparisi (eds.) Multimodal Metaphor. Mouton de Gruyter, Berlin and New York, 95-117.

Van Mulken, Margot, Rob Le Pair, and Charles Forceville (2010) "The impact of perceived complexity, deviation and comprehension on the appreciation of visual metaphor in advertising across three European countries". Journal of Pragmatics 42, 3418-3430.

Yu, Ning (2007) "Cultural identity and globalisation: Multimodal metaphors in a Chinese educational advertisement”. China Media Research 3 (2), 25-32.

Angeliki Tzanne is Associate Professor in Linguistics at the Faculty of English Language and Literature, National and Kapodistrian University of Athens. After having obtained a BA from the Faculty of Greek Philology and a BA from the Faculty of English Language and Literature, University of Athens, she pursued postgraduate studies (M.A and Ph.D.) at Lancaster University, England. Since 1999 she has been teaching at the Department of Language and Linguistics of the Faculty of English Language and Literature, University of Athens. Her research interests include Sociolinguistics, Pragmatics and Discourse Analysis, with particular emphasis on academic and media discourse. She is the author of a book (Talking at Cross-Purposes, 2000. Amsterdam: John Benjamins) and of a number of articles which have appeared in international journals and edited volumes.

Address: Angeliki Tzanne, Faculty of English Language and Literature, School of Philosophy, University Campus Zografou, Athens 157 84, Greece. [email: atzanne@enl.uoa.gr] 